\title{
Two-decade seismicity of the SE Alborz region, Iran: Reloca- tion of earthquake hypocenters using cross-correlation based time corrections
}

\author{
${ }^{1}$ Institute of Geophysics, University of Tehran \\ ${ }^{2}$ Institute of Geophysics, University of Tehran; *Corresponding author, E-mail: mrhatami@ut.ac.ir \\ ${ }^{3}$ University of Urmia
}

(Received: June 10, 2018; Revised accepted: April 21, 2019)

https://doi.org/10.18814/epiiugs/2019/019008

Located on the foothills of Alborz mountains, in northern Iran, the city of Tehran is surrounded by many active faults that have caused destructive earthquakes in the past. Two earthquakes magnitudes 4.1 and 3.6 occurred on $13^{\text {th }}$ August 2015, known as Javadabad earthquakes, affected the SE Alborz region near Tehran. In this study, we relocated 780 events with magnitude 2.0 and larger that occurred during 1996-2015, which provides an enhanced image of seismicity in the region. We manually re-picked $6845 P$-wave and 4675 S-waves arrival times on 41 seismic stations encompassing the SE Alborz regions. We then used our arrival times to relocate the earthquakes using a probabilistic method. Then we focus on improving the picked arrival times by cross-correlating the waveforms of $P$ - and $S$-waves for event pairs with similar waveforms. The differential times of event pairs for all observations were weighted based on the quality of correlations. We computed more than 220,000 and 140,000 differential times for $P$ - and $S$-wave records, respectively, and selected pairs of waveforms with coefficients of 0.7 or higher. Finally, in order to minimize the effect of inaccurate velocity structure, we applied the double-difference location method.

\section{Introduction}

Studying the earthquake location is one of the most important aspects of seismology. Locating the hypocenter and particularly the precise focal depth of an earthquake can be quite effective in the interpretation of the complex structure of a fault. Furthermore, the information regarding the fault geometry such as dip, strike and the depth on the fault plane can be useful in introducing more precise parameters for earthquake hazard assessments.

It is quite common to use arrival times picked by seismological centers to relocate earthquakes or perform seismic tomography (Gorbatov and Kennett, 2003, Miller et al., 2005; Mottaghi et al., 2010;
Maleki et al., 2013; Hejrani et al., 2014; Mousavi et al., 2015). The result of any geophysical inverse problem, including earthquake location, is highly dependent on the quality of the input data. Many studies have addressed the issue of phase picking and providing high accuracy data in earthquake location (e.g., Waldhauser and Ellsworth, 2000; Schaff et al., 2004; Husen and Hardebeck, 2010).

In addition to the importance of the input data in the earthquake location, choosing the appropriate method to solve the location problem has been a significant challenge. Due to the $3 \mathrm{D}$ heterogeneous structure of the earth, the relation between the arrival times of the seismic waves in respect with hypocenter location is nonlinear. In order to simplify the location problem, the relations applied in most of the location methods are linearized. Most of these methods and algorithms are based on principles introduced by Geiger (1912).

Using linearized methods may cause shortcomings in the location of the earthquakes as well as decreasing the precision due to pruning the higher terms of Taylor's series, especially when the hypocenter is located out of the network. Thurber (1985) showed that under circumstances that the focal depth is small compared to the epicenter (in networks with large inter-station distances) precise determination of the focal depth is impossible by linearized methods. In such cases, using higher (nonlinear) terms could resolve the shortcomings. Using the higher orders in Geiger method requires calculation of derivatives of higher orders, which become quite complicated when using $3 \mathrm{D}$ velocity models that practically providing a precise solution to the location problem is quite difficult. In order to dispose of the problems due to calculation of derivatives of higher orders, Tarantola and Valette (1982) introduced a method in which earthquakes are located using full nonlinear relations while calculation of higher order derivatives is not required. Based on construction a probability density function, this method locates the earthquake by finding a point with maximum probability, based on the construction of a probability density function. The theoretical foundations of the nonlinear probability method were outlined by Tarantola and Valette (1982) and completely revised by Tarantola (1987). A nonlinear location method based on probabilistic inverse problem (Tarantola and Valette, 1982; Tarantola, 1987) was implemented by Lomax et al., (2000) which was used in this study. In addition to the absolute 
location methods, relative earthquake relocation has been proven quite effective in minimizing the errors in location (Waldhauser and Ellsworth, 2000; Schaff et al., 2004). Waldhauser and Ellsworth (2000) introduced the relative earthquake relocation in the double difference method based on cross correlation data as well as catalogue data. As the first requisite for using this method, the hypocenters must be close enough so that one can assume that the paths of the seismic waves from the source to stations are the same.

\section{Tectonic Setting}

The studied region is located in the south-east of Tehran. According to the seismotectonic divisions by Mirzaei et al., (1998), this region is part of the seismotectonic province of Alborz-Azerbaijan which is known as the Central Alborz. The Alborz is a seismotectonic province that spans the Northern parts of Iran. The Alborz Mountain Range is bounded by the Caspian Sea subsidence from North and by the Central Iranian Plateau from South.

In determination of the boundaries of the seismotectonic state of Alborz-Azerbaijan, the Northern boundary of Alborz stretches along the Southern block of the Caspian Sea. Currently, the Southern block of the Caspian Sea is having a low strain rate and its behavior against the deforming causes is different from other parts of Iran (Jackson et al., 1995). From a geological viewpoint, the southern boundary of the seismotectonic state of Alborz-Azerbaijan is not clear. However, based on neotectonic studies, the southern boundary of this state is located on active faults like Ipak and Torud Faults. The Central Alborz part of the seismotectonic state of Alborz-Azerbaijan has experienced events with considerable magnitude in the last century. The largest and most destructive earthquake since 1900 was the Rudbar earthquake (MW = 7.4) occurred on June 20, 1990. It killed more than 40,000 people. Also, among the large earthquakes are the Baladeh earthquake $(\mathrm{Mw}=6.4)$ occurred on May 28, 2004 and Kahak earthquake of 18 June 2007. in addition to these events, other earthquakes with magnitudes between 4 and 5.5 (Mn scale) have been recorded in the region in recent years among which are Ray earthquake $\left(\mathrm{M}_{\mathrm{w}}=4.0\right.$, October 17, 2009), Javadabad earthquake $\left(\mathrm{M}_{\mathrm{W}}=4.3\right.$, August 13, 2015) and Meshkindasht earthquake $\left(\mathrm{M}_{\mathrm{W}}=5.3\right.$, December 20, 2017). In this study, we processed the complete waveform database of the south-east part of Tehran including active faults such as Pishva, Garmsar, Rameh, and parchin faults to improve the locations of the earthquakes based on cross correlation and double-difference techniques.

The seismicity map of the south-east of Tehran is shown in Fig. 1. The green box in this figure shows the studied region. As can be seen from Fig. 1, substantial instrumental events occur in this part, which indicate the activity of the faults in the region.

Based on the initial earthquake location by the Iranian Seismological Center (IRSC) as well as the International Institute of Earthquake Engineering and Seismology (IIEES), the aftershocks of Javadabad Earthquake were aggregated in the region of Pishva Fault. Located in the South East of Varamin city, Pishva Fault is about $35 \mathrm{~km}$ long with the general trend of (N38W, 33NE). Focal mechanism solutions of the recent events suggest a compressional mechanism with a left-lateral component and dipping north (Majidiniri et al., 2010). Morphotectonic studies on this fault show evidence on its activity. The slide rate of Pishva Fault has been estimated to be $0.12-0.14 \mathrm{~mm} / \mathrm{year}$ (Majidiniri et al., 2010).

\section{Data and Methods}

In order to enhance the percision of seismic phase picking and to use the waveform cross correlation technique, the seismic waveform data were used to manually pick $\mathrm{P}$ - and $\mathrm{S}$ waves. The data used in this study were provided by the Iranian Seismological Center. This network is

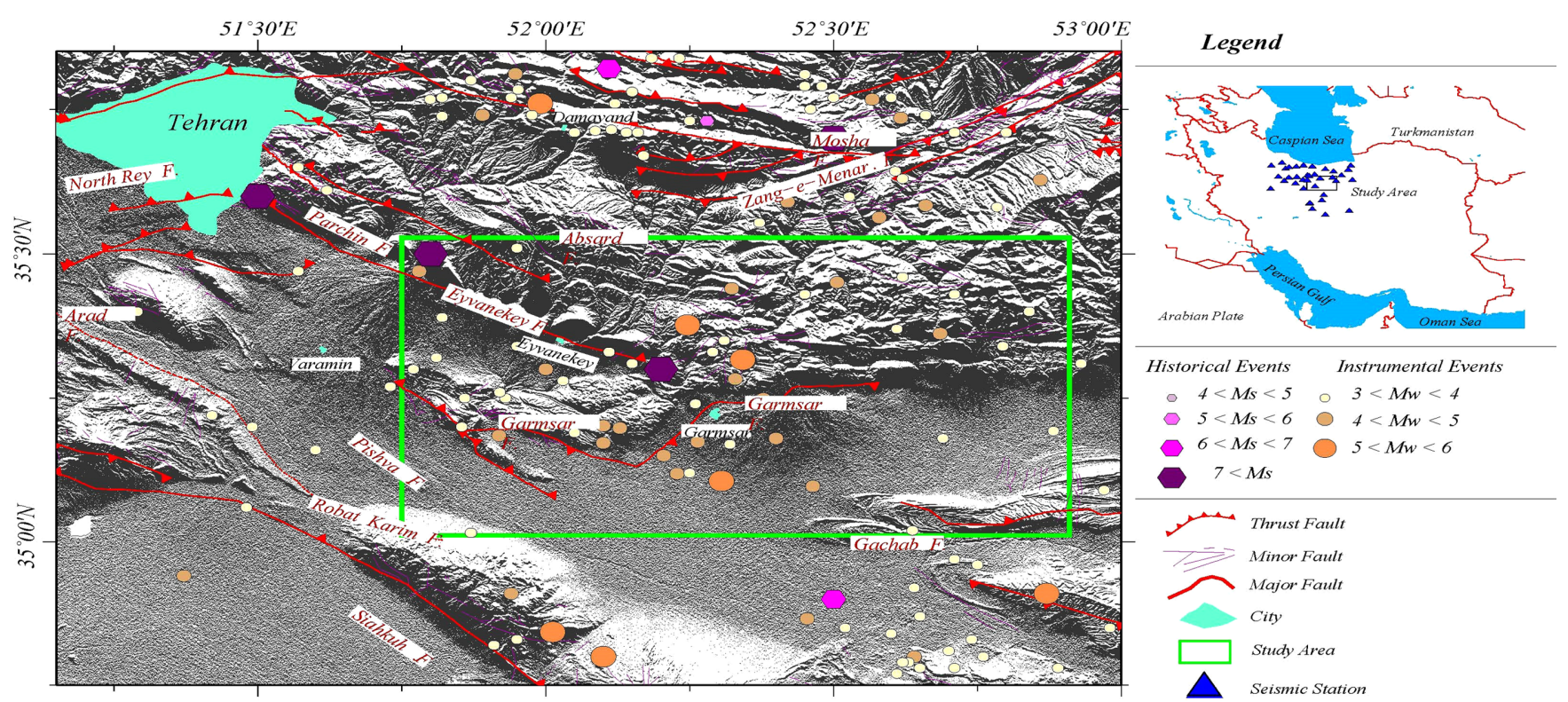

Figure 1. Seismicity map of the Eastern South of Tehran. The green box in this figure shows the studied region. The historical earthquakes (those recorded before 1900) are shown by hexagons while the instrumental ones (those recorded after 1900) are shown by circles. Blue triangles on reference map are stand for seismic stations. 
a)

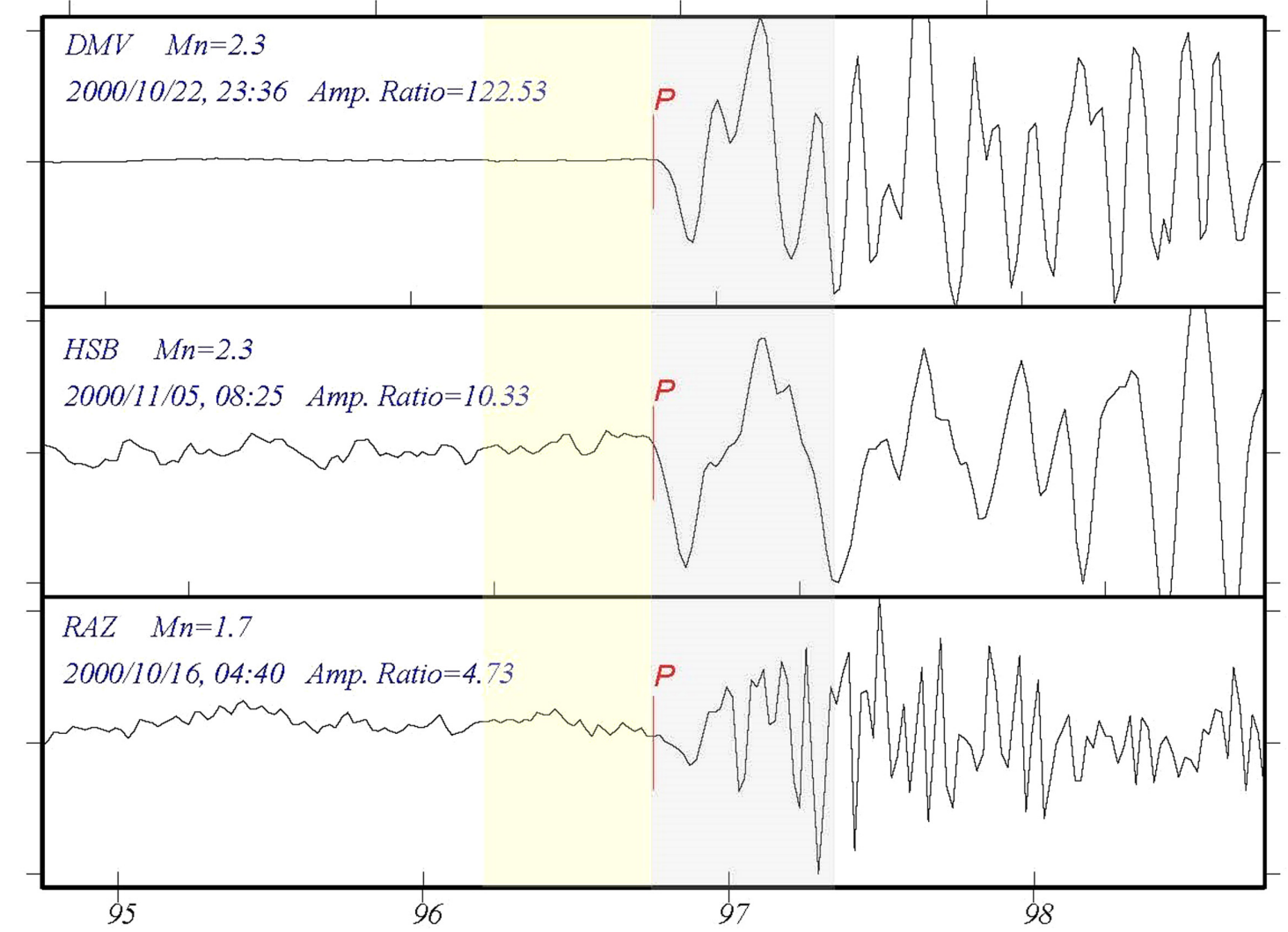

Time (sec)

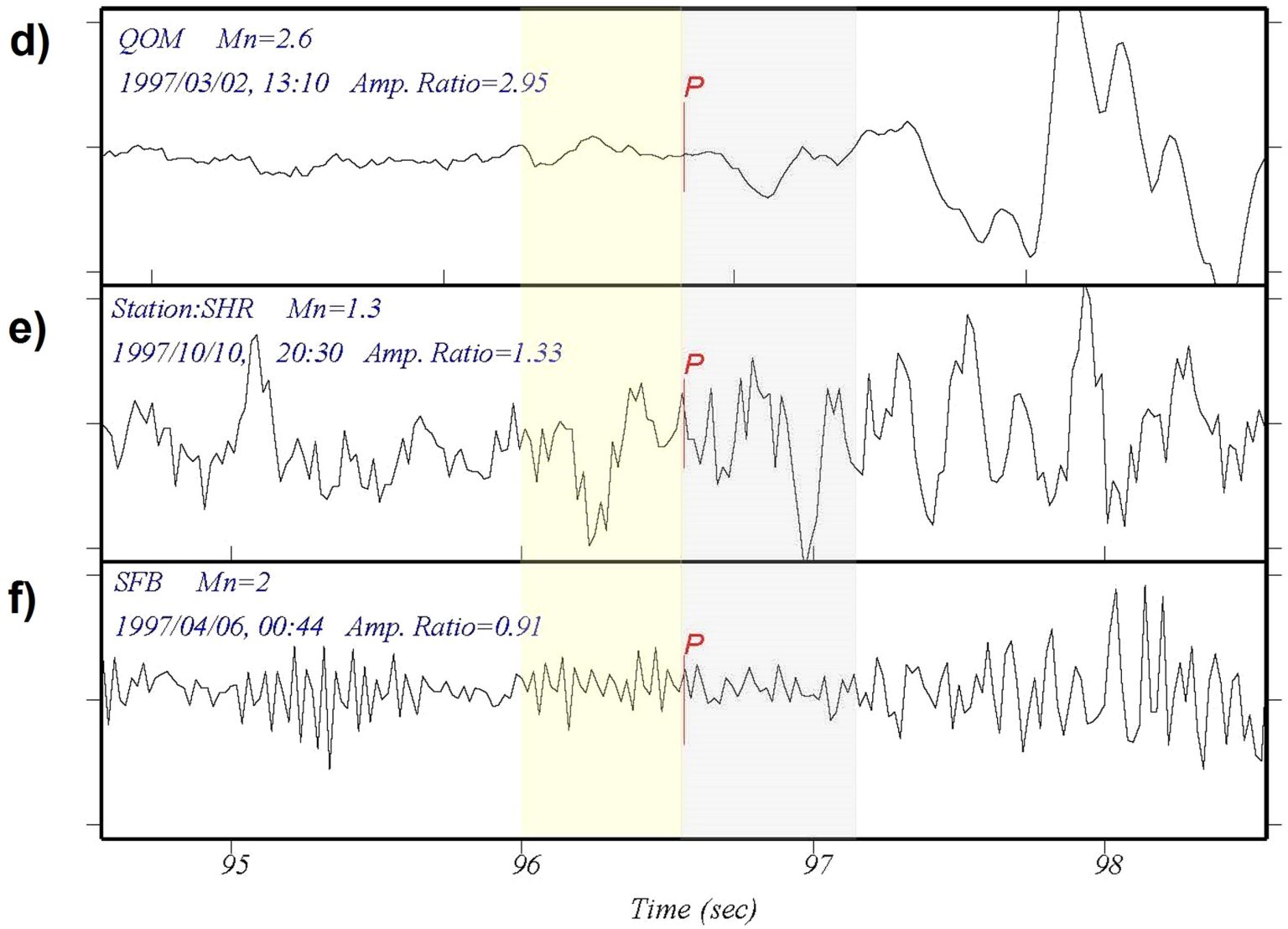

Figure 2. Assigning weights to the picked phases based on the ratio of the amplitude after the wave arrival to the amplitude before the wave arrival in a time window with a length of 0.5 second. The ratio for each record is shown on the record. Panels (a) to (f) represent different quality of picked phase respect to quality of seismic record. 
consist of short period instruments with SS1 seismometers (effective around $1 \mathrm{~Hz}$ ) as well as average-band seismic stations equipped with Trillium-40s seismometers. We analysed the records of 780 earthquakes with $\mathrm{Mn}>2$, including the 55 aftershocks of the recent Javadabad earthquake (Pishva fault), occurred during 1996-2015. Selection of a velocity model in every earthquake location problem is an important prior information. An inappropriate velocity model can introduce systematic errors into the results and the final location result is drastically influenced. In this study, based on the picked arrival time data, a velocity model was derived using the VELEST Software, but given the wide spread of the station network with respect to the hypocenters of the earthquakes, the result was not utilized and instead velocity models derived in previous studies were used. Based on the initial locations performed by various velocity models such as Ashtari et al., (2005), Abbasi et al., (2010), it turned out that velocity model by Abbasi et al., (2006) was more fitted for the seismic data of the present study. It also showed less time residuals (RMS values) compared to the velocity model by Ashtari et al., (2005). Therefore, in initial location and relocation, the velocity model by Abbasi et al., (2010) was used.

In this study, two methods for earthquake location were used. First, an initial location was calculated based on a nonlinear probabilitic method and using phases manually picked in this study. Then, using the wave- form cross correlation technique, events with high similarity were identified and clustered. On this basis, a relative location was done for the events. The method used in this study for the initial location of the earthquakes was based on the probabilistic inverse problem by Tarantola and Valette (1982) and Tarantola (1987).

The core of probabilistic method is to construct a Probability Density Function (PDF) based on minimizing difference between the observed arrival times and the calculated arrival times from an initial velocity model. This method reduces the number of parameters of the location problem from four to three parameters. A basic assumption in nonlinear methods is that the observed data uncertainty follows a Gaussian distribution i.e. it has a normal distribution all over the data. The earthquake location is deduced by seeking the maximum likelihood function (Tarantola and Valette, 1982). However, due to the nonlinear nature of the earthquake location problem as well as systematic (non-Gaussian) errors (due to the unreliable velocity model and inappropriate station coverage), results could be trapped in local minima. Finding a global minimum is a substantial challenge in earthquake location problem and in general in non-linear optimizations. This requires an exact evaluation of the PDF points scattered all around the network, which could be obtained using the Oct-Tree Importance Sampling algorithm (Lomax et al., 2000).

After the initial probabilistic approach to relocating the earthquakes

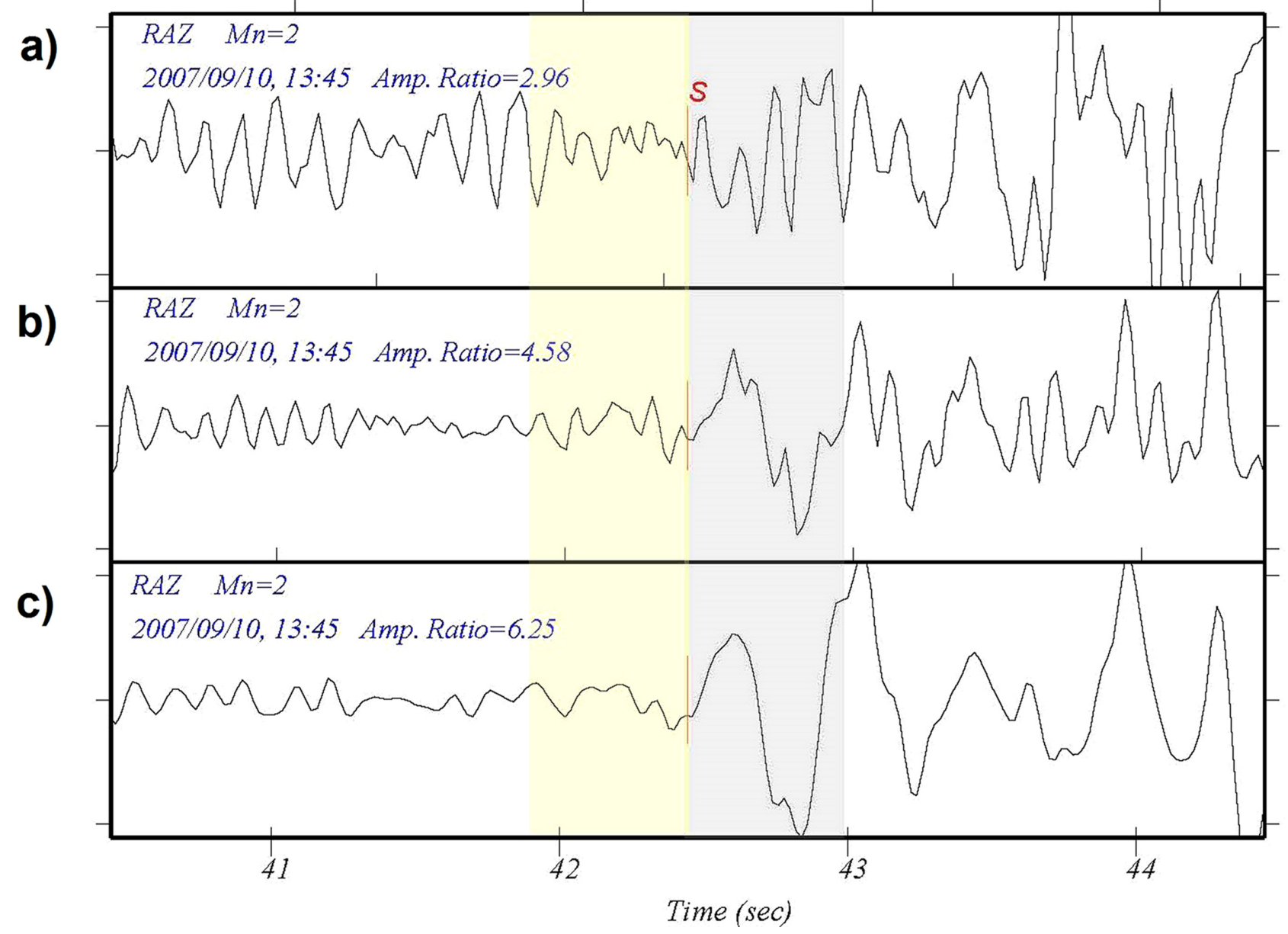

Figure 3. Reading the S phases in this study by rotating the horizontal components around the vertical axis along the arrival path of wave at the station. Panels (a) and (b) are Northern and Eastern components, respectively. Window (c) is the tangential component resulted from the rotation of the horizontal components. 

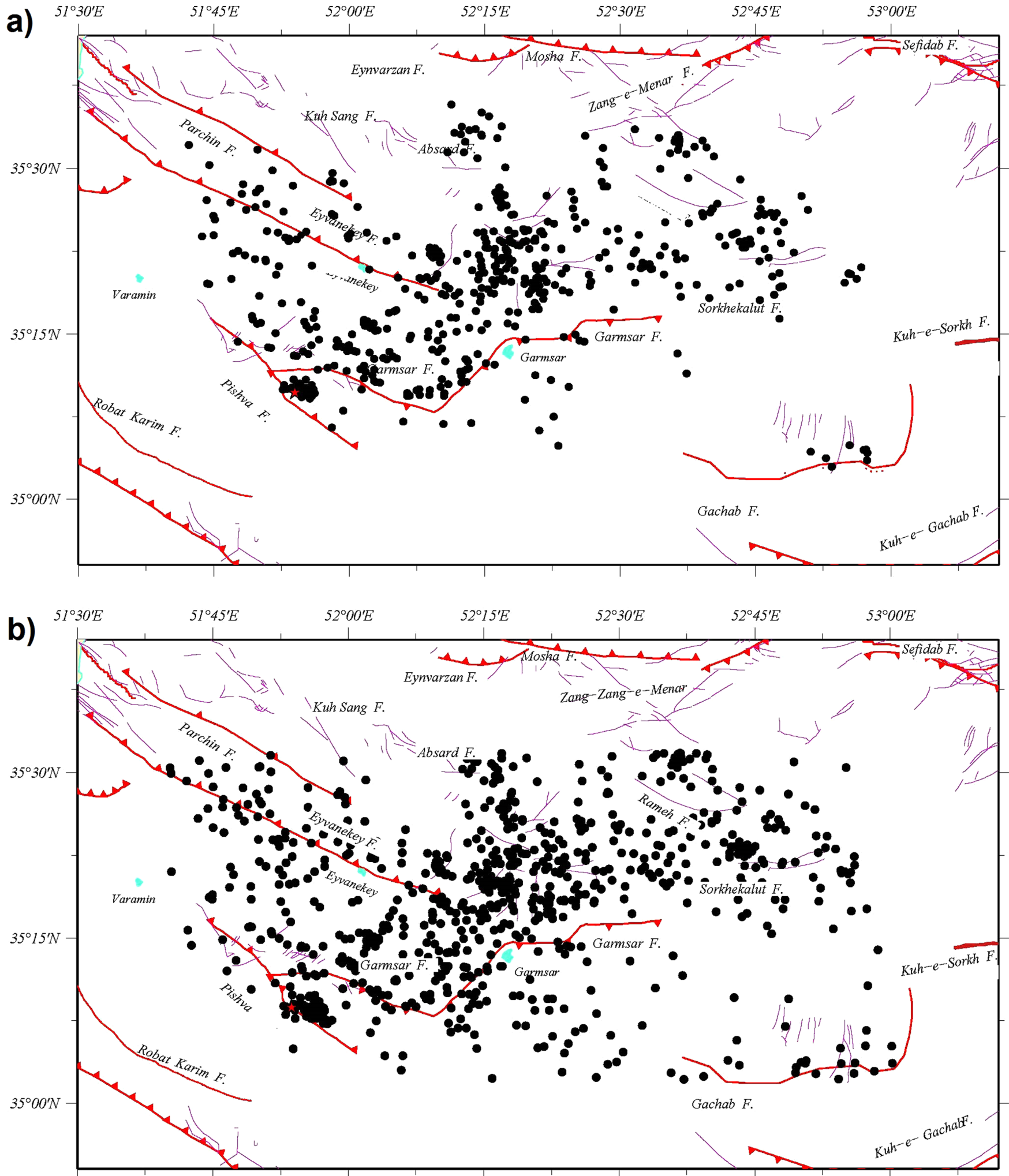
Legend

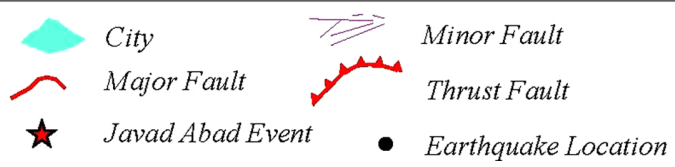

Figure 4. Locations performed for the events of the studied region. (a) Location based on and the Double Difference method and using the catalogue data. (b) Location based on the Nonlinear Probabilistic Earthquake Location method. 
using the manually picked arrival times, we apply the Double Difference method (Waldhauser and Ellsworth, 2000) to enhance the accuracy of location and reduce the effect of 3D heterogeneity of the earth. The Double Difference method can be appropriate when the events are close enough. The cross correlation technique can identify events of high similarity through finding similarities between the earthquake waveforms. The cross correlation of the waveforms (for two events recorded at the same station) provides useful data of the mutual status of two events. A high similarity between two events, in addition to the fact that it can determine the similar paths travelled from the sources to the station, can indicate a close relationship between the mechanisms of the two events and therefore assigning them to the same fault and source. Finding earthquakes with seismotectonic correlation can resolve the problems of clustering the earthquakes which is necessary for the Double Difference method (Deichmann et al., 1992).

In order to find the relations between the earthquakes and their spatial distribution as well as finding correlation between them in a cluster of earthquakes, many methods have been employed over both time and frequency domains (Nakamora, 1978; Pavlis and Booker, 1983; Deichmann et al., 1992). The cross correlation used in this study was directly performed over a time domain. The method used in this study was introduced by plantet and cansi (1988) to calculate the similarity between events with magnitudes of less than 3.0. The method was revised by Deichmann et al., (1992) in order to determine the similarity between the aftershocks.

The seismic waveform is affected by various factors such as source mechanism, 3D structure of the earth, site effect and the instrument response. Therefore, two similar seismic records at a station could be interpreted as two sources with a highly similar mechanism and sourcereceiver paths. The source effect can be assigned to the causative fault mechanism and therefore, difference in mechanism can totally affect the recorded waveform. Likewise, an identical travel path for two events is only possible if they are close enough in which case, their travel path from the source to the seismic station will be highly similar. In this manner, the waveform cross correlation technique can provide information on similarity between two events close to each other. In addition to this important fact, cross correlation is also effective in reducing the phase reading uncertainties.

\section{Results}

The first step in manual picking of the seismic phases is to filter the records to enhance the signal to noise ratio of the seismic records. However, this filtering may damage the record and change its shape of the wavelet form and the phase shift. In this study, we filtered the seismic records with a high-pass $(>0.7 \mathrm{~Hz})$ second-order Butterworth filter.

Following Baer and kradofler (1987), weights were assigned to the data according to the amplitude ratio of before and after the arrival time in a time window of half a second. Fig. 2 (a to f), shows six example records (different events recorded at different stations). We classified the quality of the seismic phases ( $\mathrm{S}$ and $\mathrm{P}$ ) into six classes to be used in the earthquake location.

Careful manual assessment of the seismic arrivals reduces the number of outliers in the arrival time data (e.g. Muksin et al., 2013; Hejrani et al., 2014; Mousavi et al., 2015; Hejrani et al., 2015; Hejrani et al., 2017; Lange et al., 2018; Hejrani et al., 2019). One of the problems that can be studied in the seismic data is the existence of more than one event on the seismic waveform record that may cause mistakes in the identification of seismic signals. Manual assessment and re-picking seismic phases generate accurate arrival time data and consequently improve the resolution of earthquake location (e.g. Muksin et al., 2014; Mousavi et al., 2015; Mousavi et al., 2017; Lange et al., 2018). IRSC arrival time data have common issues similar to other regional and local agencies, besides, in a considerable amount of waveform data, the phase type had been identified erroneously due to complications in the record such as high levels of noise. Another problem in the arrival times of IRSC Catalogue was inaccurate identification of the first break for records with high levels of noise. In this study, identification of the $\mathrm{P}$ phase became plausible by modeling the seismic phases.

Our manual re-evaluation of the IRSC data increased the number of picked phases from 6545 to 11520 . An increase in the number of high quality seismic phases, especially for the $\mathrm{S}$ phase may reduce the uncertainty of the location process.

When reading the $\mathrm{S}$ phase, all the remarks mentioned for the $\mathrm{P}$ phase were considered as well. However, given the secondary nature of the $\mathrm{S}$ phase in seismic records and conformity of Coda $\mathrm{p}$ waves with the converted phases on the $\mathrm{S}$ phase, finding the arrival time of this phase on the record is a very laborious job and quite often not possible. One of the methods for increasing the precision in recognition of the $\mathrm{S}$ phase arrival is to use the earthquake data based on the initial location in the catalogues. We picked the S-waves on the rotated horizontal radial and tangential components.

Fig. 3, shows an example of the S-wave records picked on NS, panel a) and EW, panel b) and tangential components, panel c) for the event 2007/09/10 with magnitude $\mathrm{Mn}=2.0$. By rotation of the East and North components into radial and tangential components ( $\mathrm{R}$ and $\mathrm{T})$, the position of the $\mathrm{S}$ phase on the tangential component becomes more recognizable and its arrival time will be determined with more precision.

The 780 earthquakes occurred in this region during 1996 to 2016 were examined and their seismic phases were re-picked and extracted from seismic waveforms. After this step, each phase was assigned a weight proportional to its quality and and were used in the probabilistic non-linear inversion for the initial location of the earthquake. After an appropriate initial location for all events, the cross correlation technique was used to identify the similar events. Events with more than $70 \%$ similarity in at least four stations were selected. Fig. 4 compares the results of the initial location based on the nonlinear probabilistic method (panel b) with the relocation based on double difference method using catalog data (panel a).

Fig. 5 shows how the similarity coefficients for two waveforms were calculated in a given time window for both $\mathrm{P}$ and $\mathrm{S}$ phases. Besides, utilizing a filter in noise reduction and finding the similarities between the signals may lead into more realistic results for the similarity of two seismic signals. In this study, given the inter-station distances and distribution of the events in the network of stations, a 1-10 Hz Butterworth band pass filter was used. For events that their similarities were measured using the cross-correlation method and relocated using Double Difference method, Fig. 6 provides a comparison with the 
a)

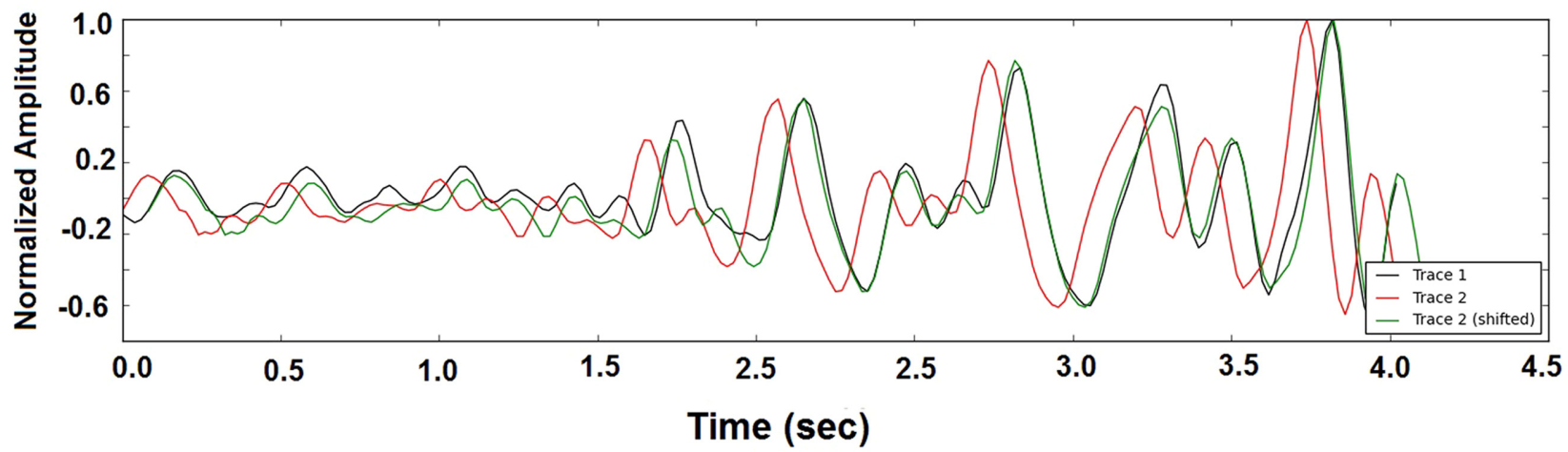

b)

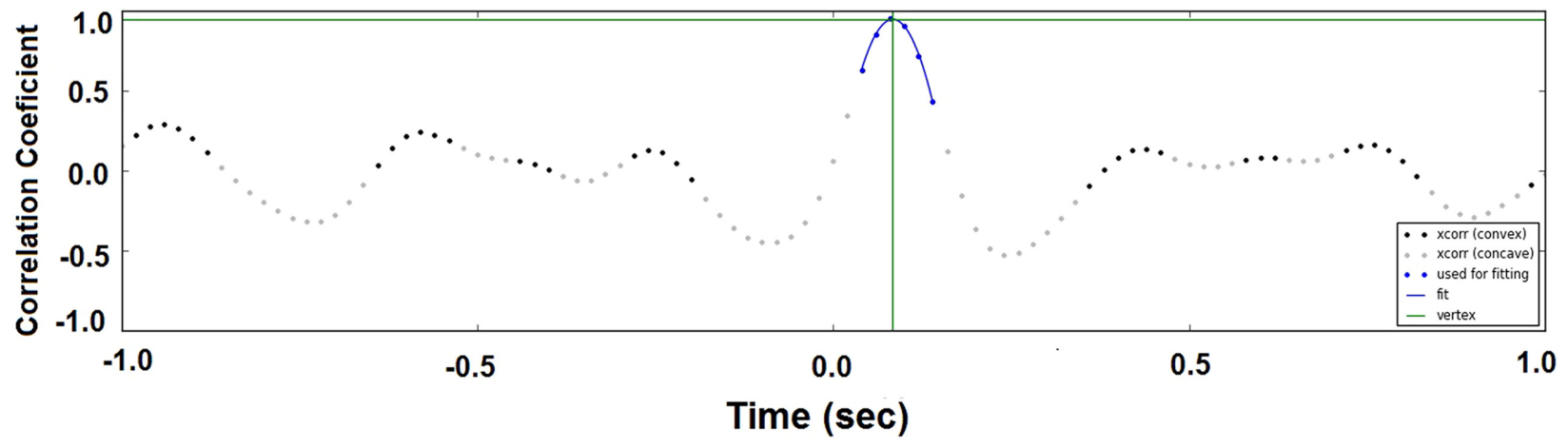

c)

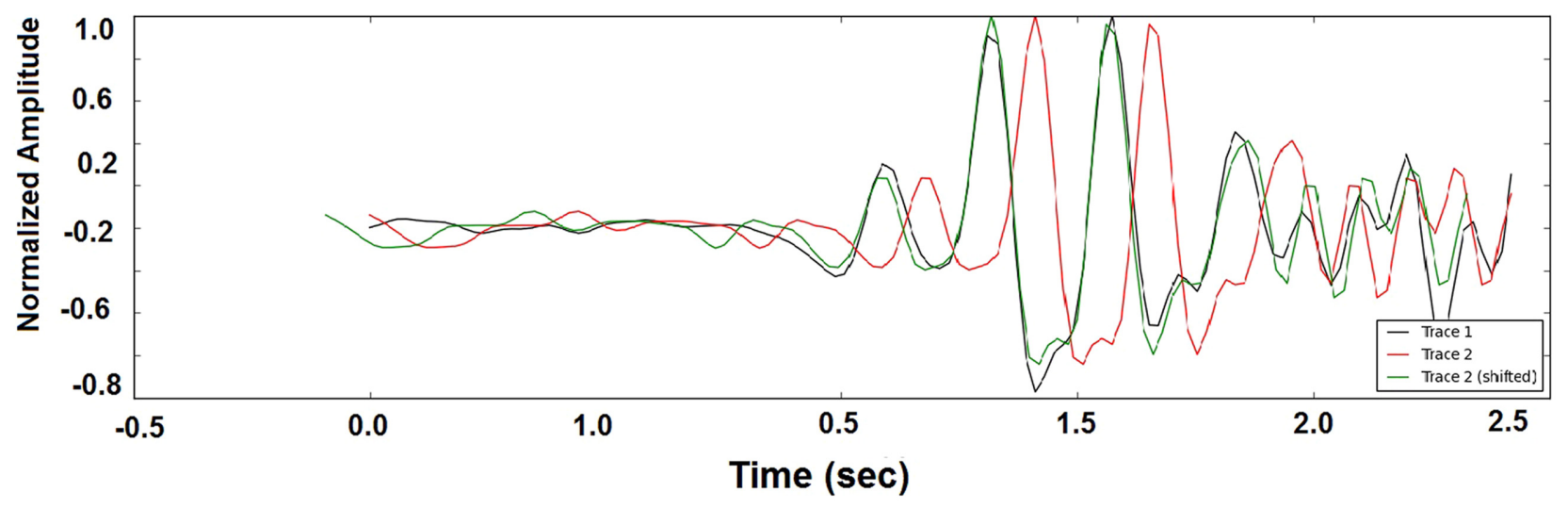

d)

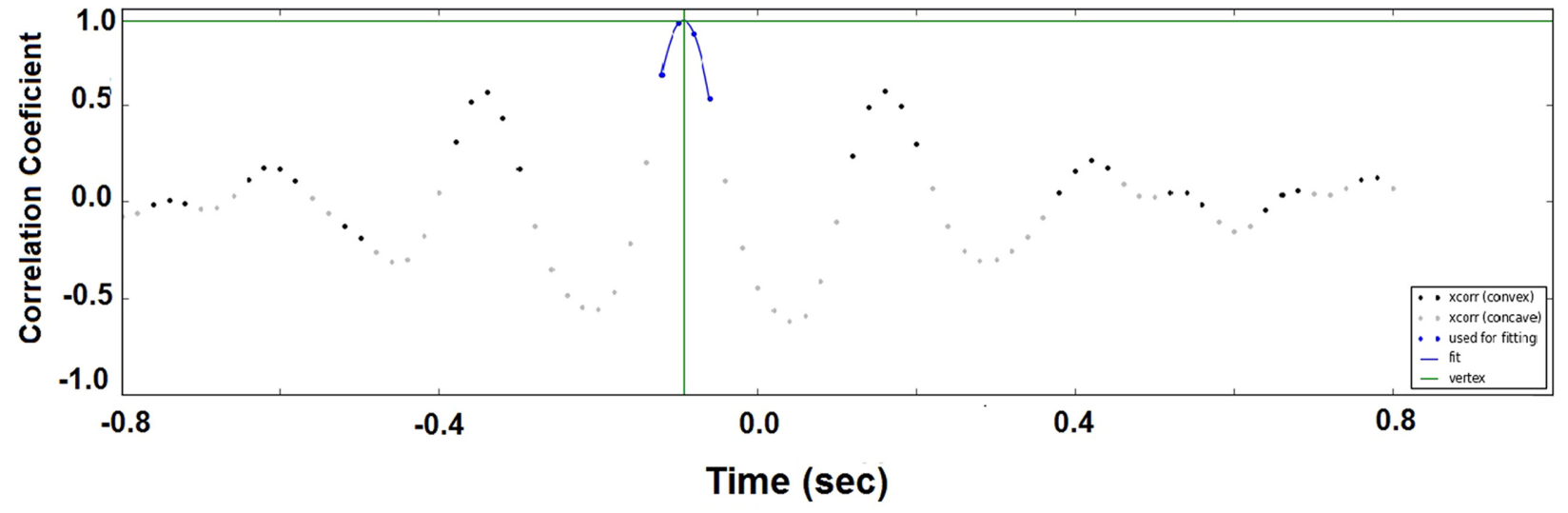

Figure 5. Calculation of the correlation coefficients for two records (of Javadabad aftershocks) in the Sefidab Station (SFB). (a) Finding similarities around the $S$ phase. (b) Respective correlation coefficient values for $S$ phase following the approach by Deichmann et al., (1992) (c) Finding similarities around the P phase (d) Respective correlation coefficient values for P phase following the approach by Deichmann et al., (1992). The upper windows show the status of the two records. The lower windows in each section depict how the similarity function coefficients are calculated. $91 \%$ similarity was found for the two records. 


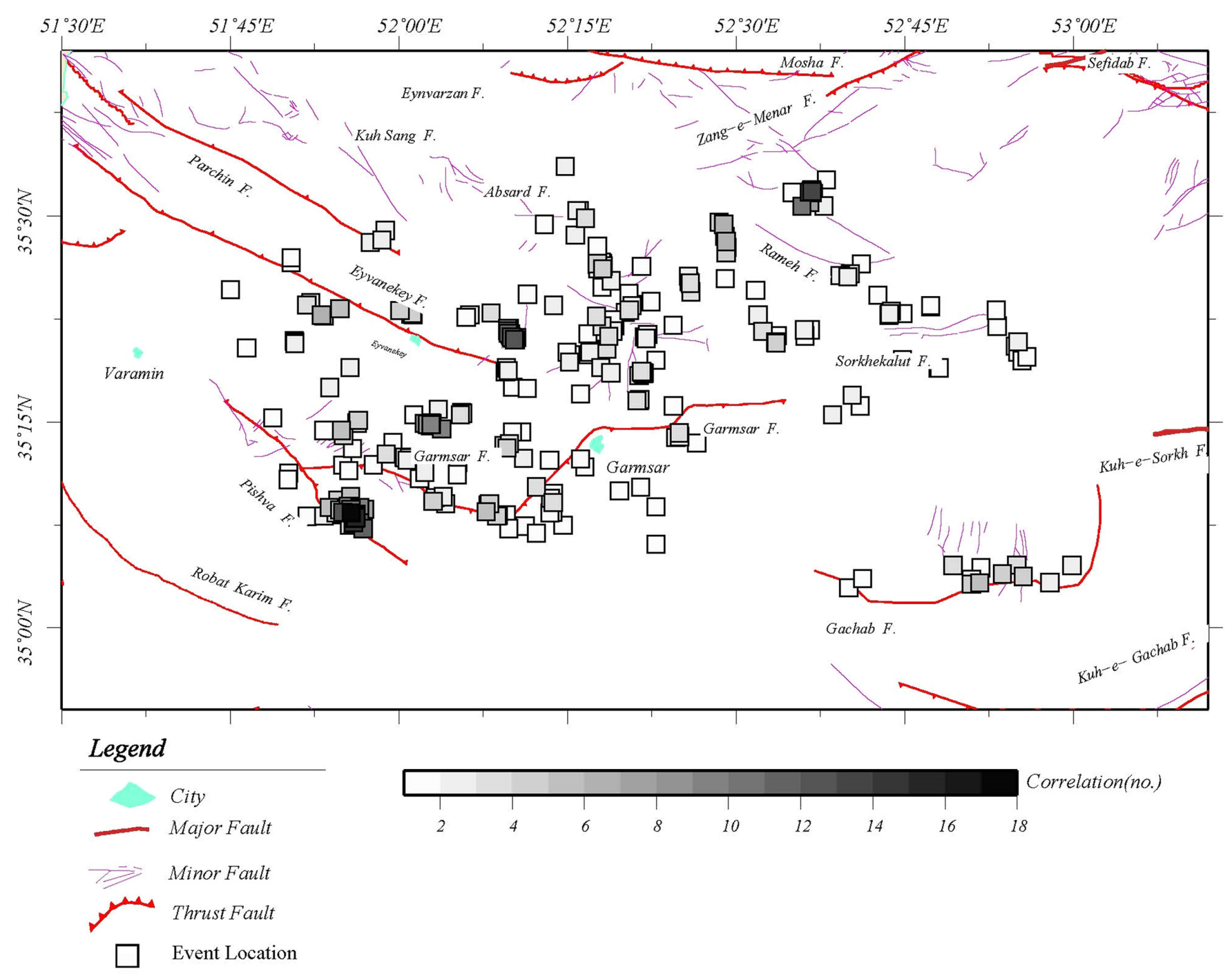

Figure 6. The map of earthquake locations based on the Double Difference method and using cross correlation data. The repetition level of events with more than $70 \%$ similarity in the studied region is shown with a grayscale spectrum. The highest repetition level of an earthquake was 18 times for a Javadabad event.

results of probabilistic inversion.

Fig. 6 shows the occurrence of similar events in terms of their repetition number with more than $70 \%$ similarity. Most of similar events with different correlation coefficient were investigated visually whether correlation coefficient represent the event similarity or not. Fig. 7 shows the number of records with more than $70 \%$ similarity recorded at IRSC seismic network.

Finally, using the double difference method and cross correlation technique, a total of 590 events were relocated for the studied region while the location uncertainty was estimated to be less than $2 \mathrm{~km}$, graphs (a), (b) and (c) from Fig. 8, compare the location uncertainties of the initial locations performed by the nonlinear method and Double Difference method based on the catalog data. In addition, in graphs (d), (e) and (f) from Fig. 8, the location uncertainties of the relocations by the Double Difference method based on the two different set, cross correlation and catalog data are compared. Compared to the initial location and the data in the catalogue, location uncertainties were considerably decreased using the double difference method. The RMS values, azimuthal gaps and the distances from the nearest station to the epicenter of the earthquakes are given in graphs (g), (h) and (i) from Fig. 8. To ensure reliable similarity detected using waveform cross correlation, waveform similarity investigated for all events visually.

\section{Discussion and Conclusions}

This study presents results of carefully analyzed seismic phases to relocate events in the South Alborz region from 1996 to 2015. The seismic phases have been re-picked based on carefully manual phase picking and each phase weighted according to its quality. A comparison of the locations by variety data sets showed that hypocentral errors reduced to some extent indicating more consistency with known fault trends. Cross correlation data gave an improvement in relocations. In addition, one of the advantages of cross correlation data is to identify repeating earthquakes (Fig. 9). Seismic networks do not report arrival time uncertainties, and it is quite rare for an analyst to make a realistic 
a)

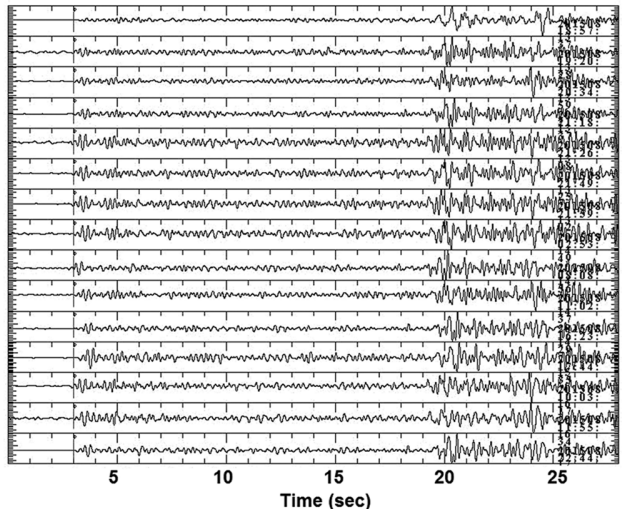

c)

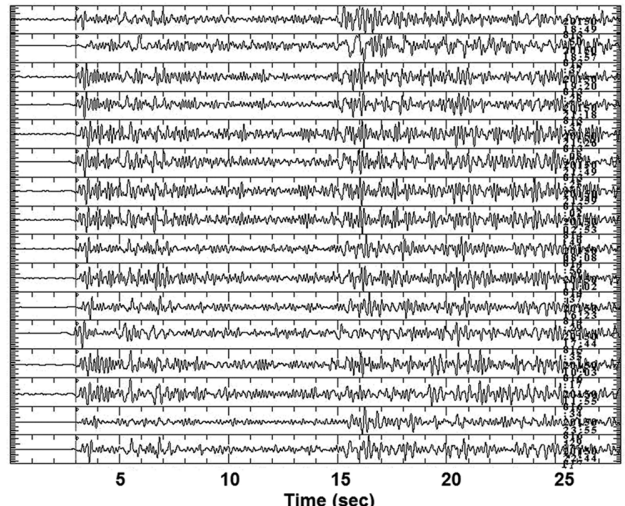

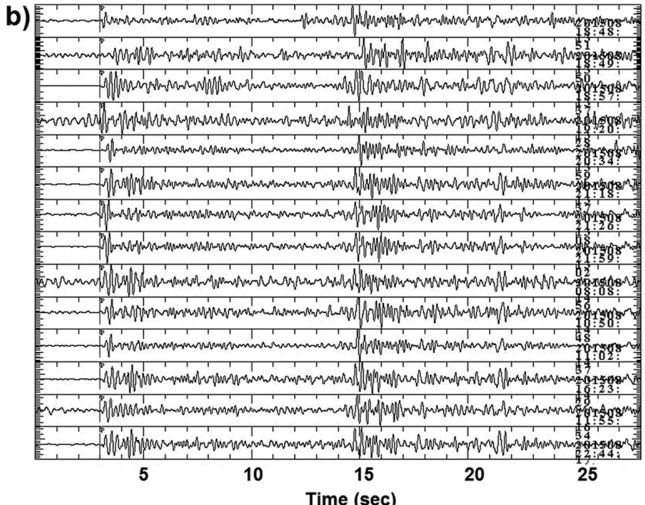

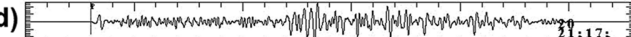

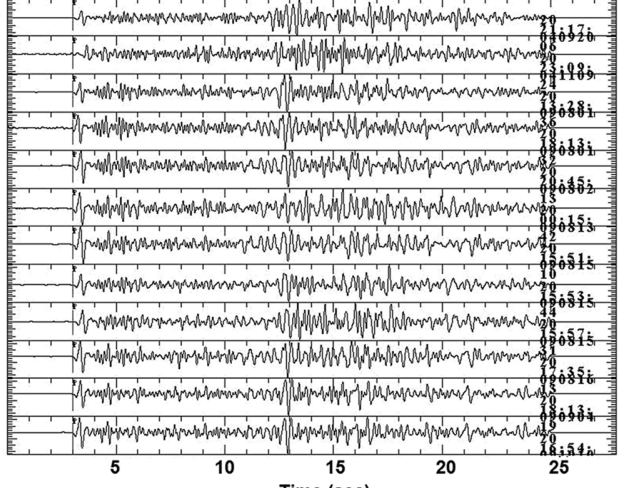

Figure 7. Waveforms of the repetitive earthquakes with more than $70 \%$ similarity in the studied region. The events were related to the Javadabad aftershocks. Similar records respectively belong to stations (a) KRSH, (b) LAS, (c) QOM, (d) SFB.
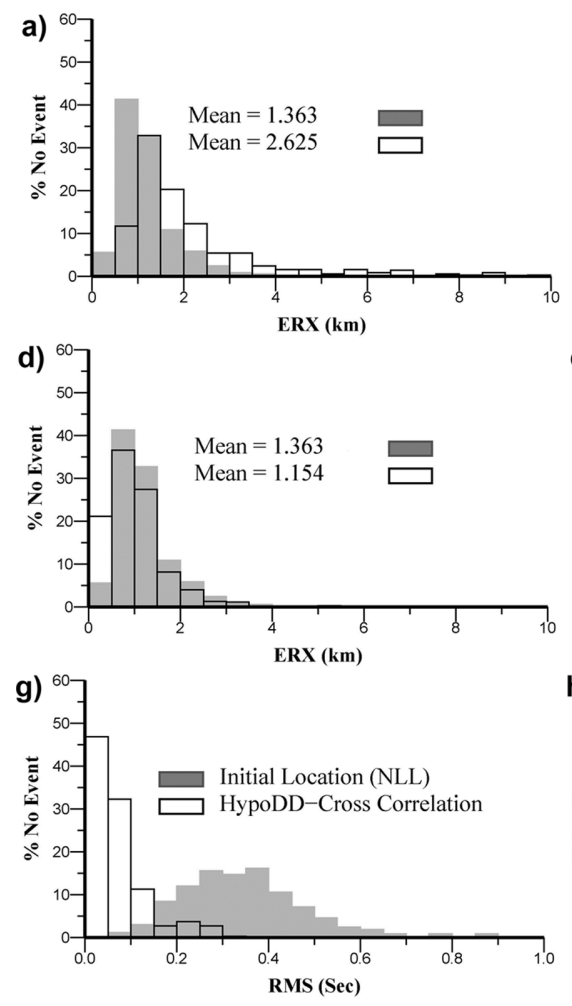
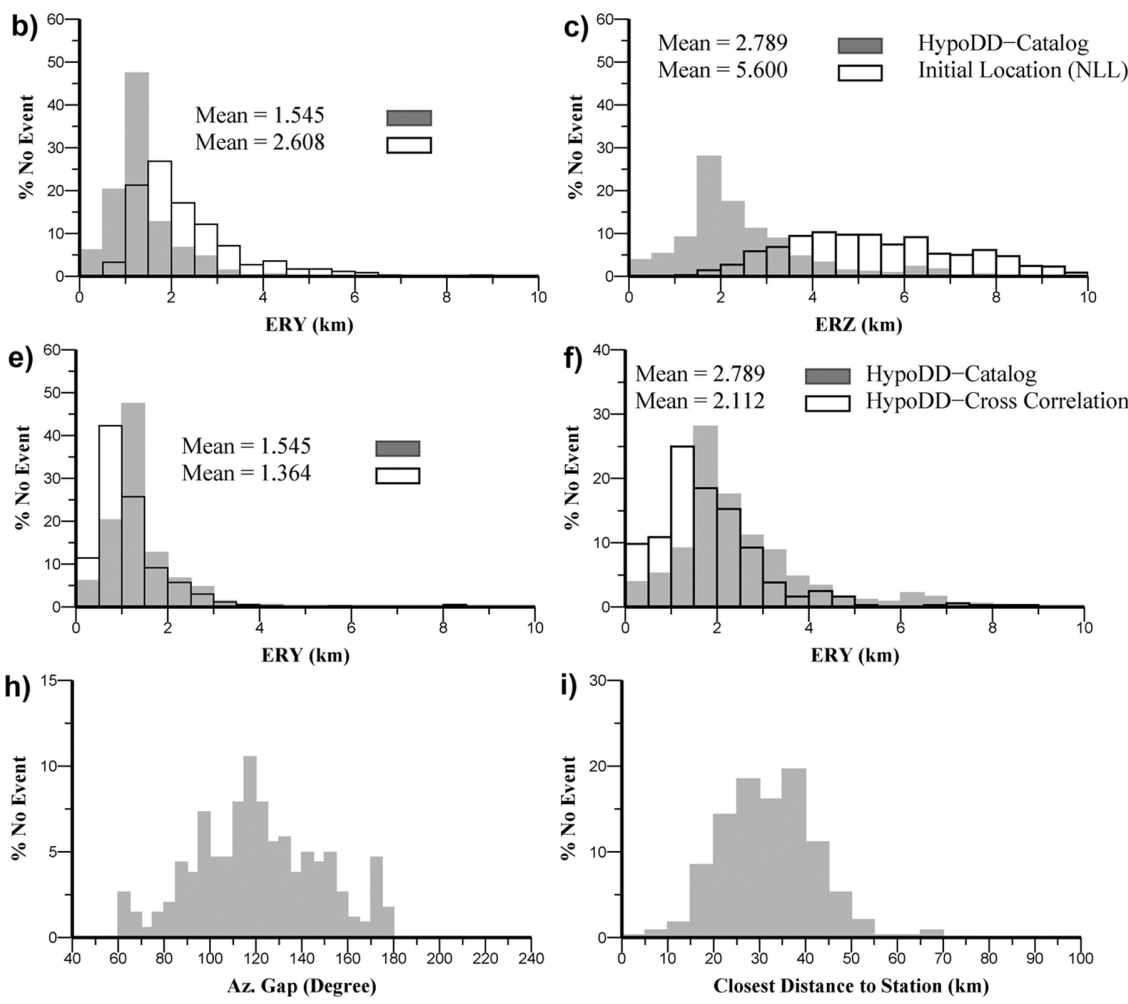

Figure 8. Statistical graph of the results acquired in this study. Graphs (a), (b) and (c) respectively compare the errors in longitude, latitude and depth of the earthquakes for the results from the Double Difference method (cross correlation data) and initial location by the probability nonlinear method. Graphs (d), (e), and (f) respectively compare the errors in longitude (ERX), latitude (ERY) and depth (ERZ) of the earthquakes for the results from the Double Difference method using the cross correlation data and the catalogue. Graph (g) shows the time residual for the results from the Double Difference method (cross correlation data) compared to the results by the initial location by the probability nonlinear method. Graphs (h) and (i) respectively show the azimuthal gap and the distance from the nearest station to the epicenter. 


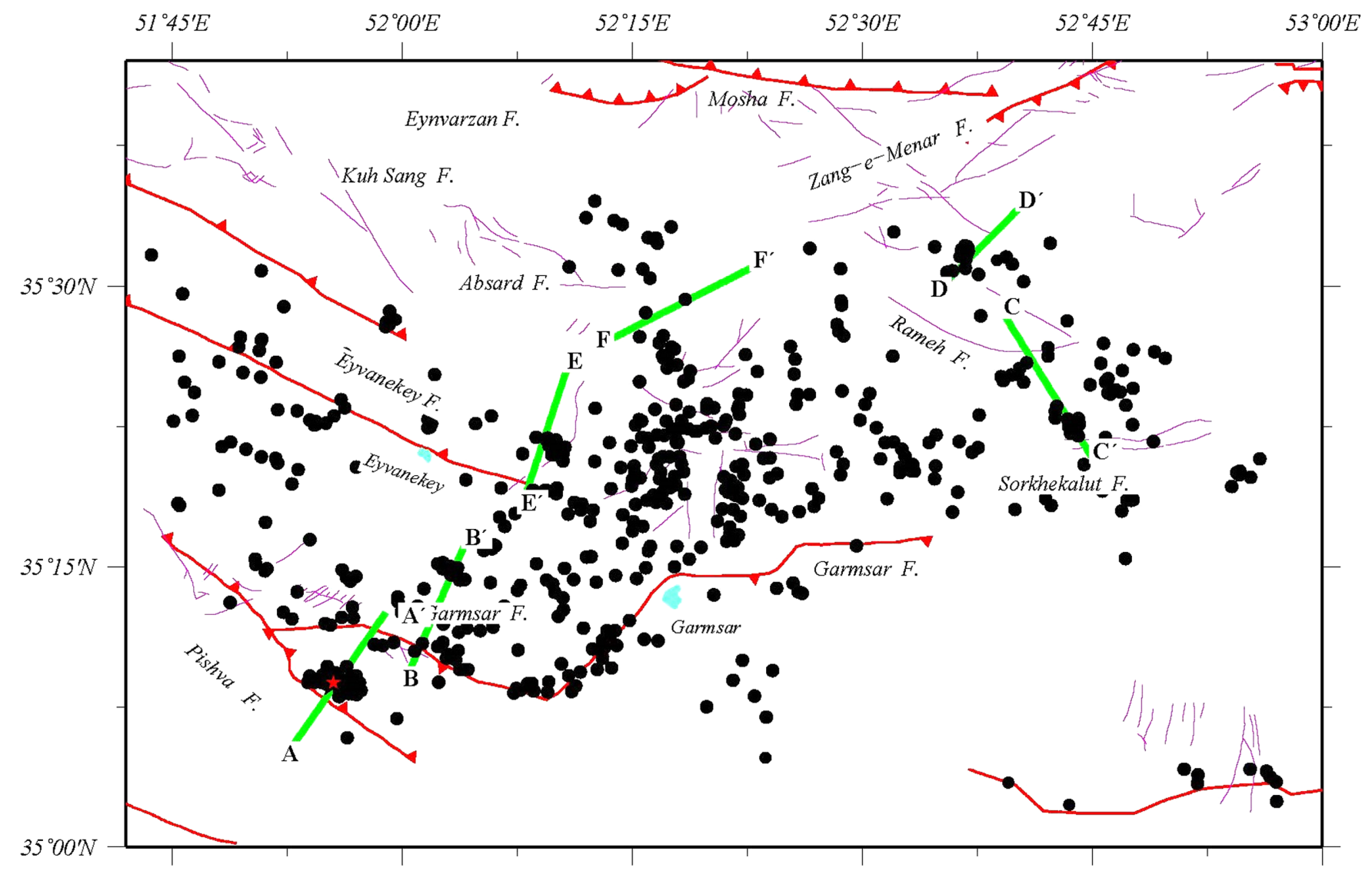

\section{Legend

City Major Fault
Thrust Fault
Earthquake Location

Figure 9. Location of earthquakes using the Double Difference method and cross correlation data. Main Javadabad Earthquake is shown with red star. The green lines show the places where the cross-sections in Figure 10 are depicted.

quantitative estimate of picking error. Thus, repeating earthquakes identified by this study can be directly used to quantify systematic picking errors in the IRSC.

The cross sections perpendicular to the known fault trends are demonstrated in Fig. 10. The most repeating earthquakes are located in the south of Zang-e Menār Fault (D-D' cross-section), Rameh Fault (C-C' cross-section), North of Garmsar Fault (B-B' cross-section), Absard Fault (F-F' cross-section), the Far East part of Eivankey Fault (E-E' cross-section) and Pishva Fault (Javadabad Earthquake aftershocks, A-A' cross-section).

In the B-B' cross-section, a marked trend with an upright slope is observed which is located in the North of Garmsar fault. Given the trend observed on the map and the cross-section, it seems that an active fault with a West-East trend could be identified in this region. In all cases mentioned above (the relocated events based on the waveform similarity and double difference method), aggregation of the earthquakes have increased compared to the initial locations and the uncertainty in location and depth was reduced to less than $2 \mathrm{~km}$.

The seismic activity in this region coming from our relative loca- tions show increased agreement with major active quaternary faults. Our results demonstrate the structural trends, allowing delineation of the fine coherent features changing from approximately $\mathrm{N} 110^{\circ}$ in Western Alborz to N80 in Eastern Alborz (i. e. see Allen et al., 2003; Vernant et al., 2004).

According to epicenter distribution around the Parchin fault, there are probably several faulting systems present with different strikes. Most of structural features, identified by a narrow topographical trace at the surface together with epicentral distributions, confirms the Vshape seismicity of this region with faults trending northwestsoutheast in the south western side and trending northeast-southwest in the south eastern side. In general, the relative relocations show increased agreement with major active faults, and we see a sharpening of seismicity resulting in a number of notably coherent linear trends where cross correlation data used. The absolute and relative relocations discussed in this study are an improvement in part because of both carefully phase picking process and reduced uncertainties by cross correlations. 

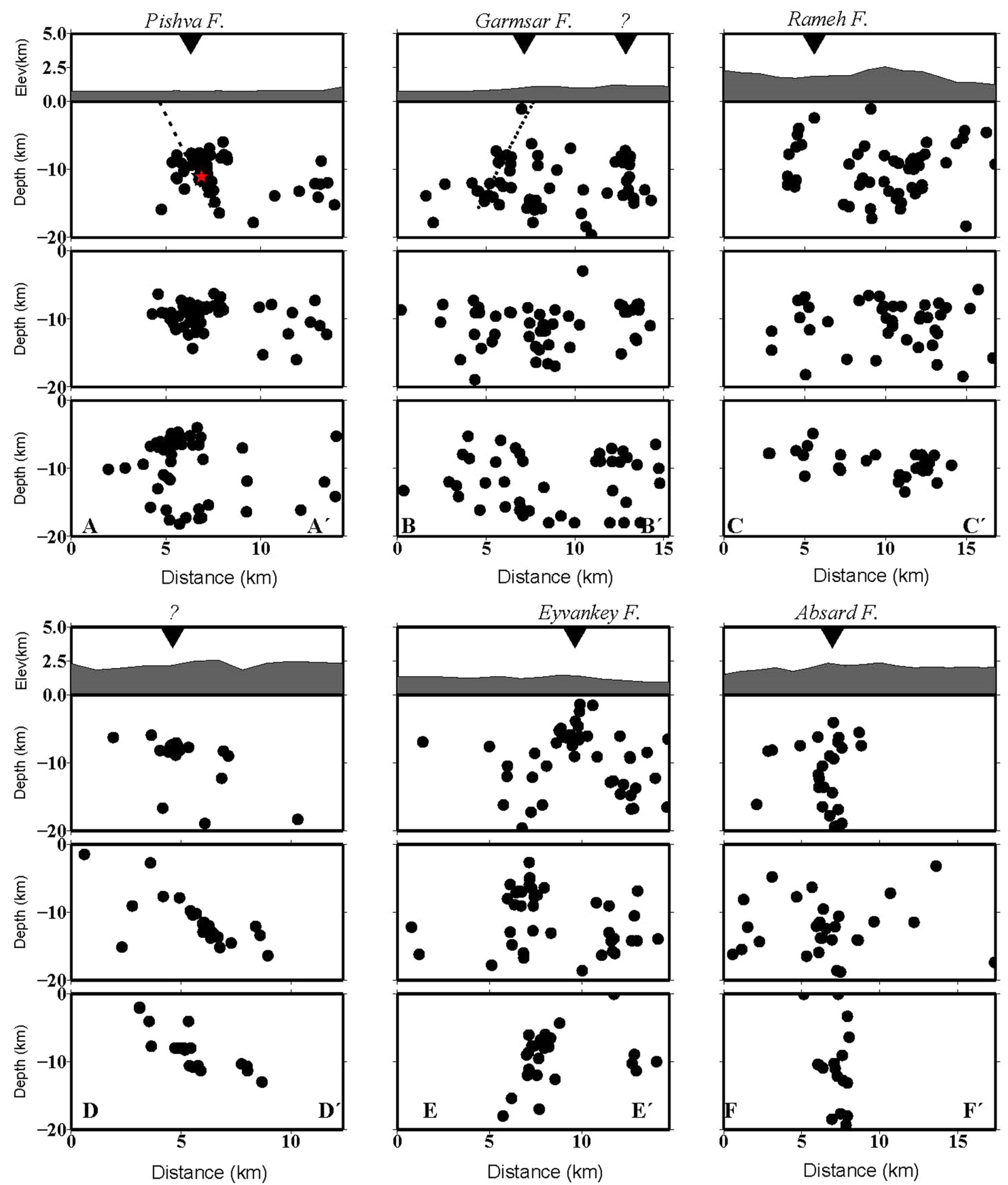

Figure 10. The vertical cross-sections through relocated earthquake data. The cross-section location profiles are shown in Fig. 9. In each panel, the upper plot shows elevation variations along the profile, the second plot shows IGUT catalog seismicity located using hypo 71 , and the third plot shows relocation results using nonlinear probabilistic method and the bottom plot shows final relocation results using double difference method. The northward dip of the Pishva and the southward dip for Garmsar faults can be seen in cross-sections AA' and BB'. The southwestward dipping structure of the Rameh Fault is clear in cross-sections CC'. The hypocenter of the Mw 4.1 Javadabad earthquake, which occurred on 13 August 2015, is shown by the red star in cross-section $A A^{\prime}$ '. 


\section{Acknowledgments}

We hereby appreciate the Iranian Seismological Center for providing us with their data (http://irsc.ut.ac.ir/ last accessed March 2016). NLL software, developed by A. Lomax (www.alomax.net/nlloc) last accessed 2017), HypoDD software, developed by Felix Waldhauser (https://www.ldeo.columbia.edu/ felixw/hypoDD.html). Some plots were made using the Generic Mapping Tools (GMT) version 4.2.1 (Wessel and Smith 1998; www.soest.hawaii.edu/gmt, last accessed March 2017). We would also like to thank the Associate Editor, Dr. Osamu Kazaoka and two anonymous reviewers for their constructive comments and useful suggestions.

\section{References}

Abbassi, A., Nasrabadi, A., Tatar, M., Yaminifard, F., Abbassi, M.R., Hatzfeld, D., and Priestley, K., 2010, Crustal velocity structure in the southern edge of the Central Alborz (Iran). Journal of Geodynamics, v. 49, pp. $68-78$.

Allen, M.B., Ghassemi, M.R., Sharabi, M., and Qoraishi, M., 2003, Accomodation of late Cenozoic oblique shortening in the Alborz range, northern Iran. J. Struct. Geol., 25, 659-672.

Ashtari, M., Hatzfeld, D., and Kamalian, N., 2005, Microseismicity in the region of Tehran. Tectonophysics, v. 395-3-4, pp. 193-208.

Baer, M. and Kradolfer, U., 1987, An automatic phase picker for local and teleseismic events. Bulletin of the Seismological Society of America, v. 77, pp. 1437-1445.

Deichmann, N. and Garcia-Fernandez, M., 1992, Rupture geometry from high-precision relative hypocentre locations of microearthquake clusters. Geophysical Journal International, v. 110, pp. 501-517.

Geiger, L., 1912, Probability method for the determination of earthquake epicenters from the arrival time only, translated from Geiger's 1910 German article. Bulletin of Saint Louis University, v. 8-1, pp. 56-71.

Gorbatov, A. and Kennett, B.L.N., 2003, Joint bulk-sound and shear tomography for Western Pacific subduction zones, Earth and Planetary Science Letters v. 210, 527-543.

Hejrani, B., Balling, N., Jacobsen, B.H., and England, R., 2017, Uppermantle velocities below the Scandinavian Mountains from P- and Swave traveltime tomography, Geophysical Journal International, v. 208(1), pp. 177-192.

Hejrani, B., Balling, N., Jacobsen, B.H., and Tillmann, F., 2015, Uppermantle P- and S-wave velocities across the Northern Tornquist Zone from traveltime tomography, Geophysical Journal International, v. 203 (1), pp. 437-458.

Hejrani, B., Jacobsen, B.H., and Balling, N., 2014, Teleseismic tomography when stations follow profiles: pitfalls and remedies, Seismological Research Letters, v. 85, 997-1003.

Hejrani, B., Balling, N., Jacobsen, B.H., and Nielsen, S.B., Is high topography around North Atlantic correlated with seismic images of uppermantle? Submitted to Geophysical Research Letters, 2019.

Husen, S. and Hardebeck, J.L., 2010, Earthquake location accuracy, Community Online Resource for Statistical Seismicity Analysis. Available at http://www.corssa.org, doi: 10.5078/corssa-55815573.

Jackson, J., Haines, J., and Holt, W., 1995, The accommodation of ArabiaEurasia plate convergence in Iran. Journal of Geophysical Research, v. 100, pp. 15205-15219.

Lange, D., Tilmann, F., Henstock, T., Rietbrock, A., Natawidjaja, D., and
Kopp, H., 2018, Structure of the central Sumatran subduction zone revealed by local earthquake travel-time tomography using an amphibious network, Solid Earth, v. 9, 1035-1049.

Lomax, A., Virieux, J., Volant, P., and Berge-Thierry C., 2000, Probabilistic earthquake location in 3D and layered models In: Thurber C.H., Rabinowitz N. (eds) Advances in Seismic Event Location, Modern Approaches in Geophysics. Springer, Dordrecht, v. 18, pp. 101-134, doi: 10.1007/978-94-015-9536-0-5.

Majidiniri, T., Nazari, H., Qarashi, M., and Talebian, M., 2010. Paleoseimology study on Pishva fault (South Tehran), Iran. Proceedings of European Geosciences union General assembly, 2010, European Geosciences union, Vienna, Austria, p. 1511.

Maleki, V., Shomali, Z.H., Hatami, M.R., Pakzad M., and Lomax, A., 2013, Earthquake relocation in the Central Alborz region of Iran using a nonlinear probabilistic method. Journal of Seismology, v. 17-2, pp. 615-628.

Miller, M.S., Gorbatov, A., and Kennett, B.L.N., 2005, Heterogeneity within the subducting Pacific slab beneath the Izu-Bonin-Mariana arc: Evidence from tomography using 3D ray tracing inversion techniques, Earth and Planetary Science Letters, v. 235, 331-342.

Mirzaei, N., Gao, M., and Chen, Y.T., 1998, Seismic source regionalization for seismic zoning of Iran: Major seismotectonic provinces. Journal of Earthquake Prediction Research, v. 7, pp. 465-495.

Mousavi, S., Bauer, K., Korn, M., and Hejrani, B., 2015, Seismic tomography reveals a mid-crustal intrusive body, fluid pathways and their relation to the earthquake swarms in West Bohemia/Vogtland, Geophysical Journal International, vol. 203, no. 2, pp. 1113-1127.

Mousavi, S., Haberland, C., Bauer, K., Hejrani, B., and Korn, M., 2017, Attenuation tomography in West Bohemia/Vogtland, Tectonophysics, v. 695 , pp. $64-75$.

Mottaghi, A.A., Rezapour, M., and Yaminifard, F., 2010, Double-Difference relocation of earthquake hypocenters along the southern flank of the Central Alborz, Iran. Bulletin of the Seismological Society of America, v. 100, pp. 2014-2023.

Muskin, U., Bauer, K., and Haberland, C., 2013, Seismic Vp and Vp/Vs structure of the geothermal area around Tarutung (North Sumatra, Indonesia) derived from local earthquake tomography, Journal of Volcanology and Geothermal Research, v. 260, pp. 27-42.

Muksin, U., Haberland, C., Nukmanac, M., Bauer, K., and Weber, M., 2014, Detailed fault structure of the Tarutung Pull-Apart Basin in Sumatra, Indonesia, derived from local earthquake data, v. 96, pp. 123-131.

Nakamura, Y., 1978, A1 Moonquakes: Source distribution and mechanism. Proceedings of the 9th lunar and planetary science conference, 1978, Marine Science Institute. Houston, Texas, pp. 3589-3607.

Pavlis, G., and Booker, J., 1983, Progressive multiple event location (PMEL), Bull. Seism. Soc. Am. v. 73, 1753-1777.

Plantet, J.L., and Cansi, Y., 1988, Accurate epicenters location with a large network example of the 1984/1985 Remiremont sequence. Seismic hazard in Mediterranean Regions, Kluwer Academic Publisher, Boston-London, pp. 347-358.

Schaff, D.P., Bokelmann, G.H.R., Ellsworth, W.L., Zanzerkia, E., Waldhauser, F., and Beroza, G.C., 2004, Optimizing correlation techniques for improved earthquake location. Bulletin of the Seismological Society of America, v. 94, pp. 705-772.

Tarantola, A., 1987, Inverse problem theory: Methods for data fitting and model parameter estimation. Elsevier, Amsterdam, 613 p.

Tarantola, A. and Valette, B., 1982, Inverse problems = quest for information. Journal of Geophysics, v. 50, pp. 159-170.

Thurber, C.H., 1985, Nonlinear Earthquake Location: Theory and example. Bulletin of the Seismological Society of America, v. 75-3, pp. 779-790.

Vernant, P., Nilforoushan, F., Chéry, J., Bayera, R., Djamour, Y., Masson, F., Nankali, H., Ritz, J., F., Sedighi, M., and Tavakoli, F., 2004, Deci- 
phering oblique shortening of central Alborz in Iran using geodetic data. Earth and Planetary Science Letters 223,177-185.

Waldhauser, F. and Ellsworth, W.L., 2000, A double-difference earthquake location algorithm: method and application to the northern Hay- ward Fault, California. Bulletin of the Seismological Society of America, v. 90 , pp. $1353-1368$.

Wessel, P., and Smith, W., H., F., 1998, New, improved version of generic mapping tools released, Eos Trans. AGU 79, 579.

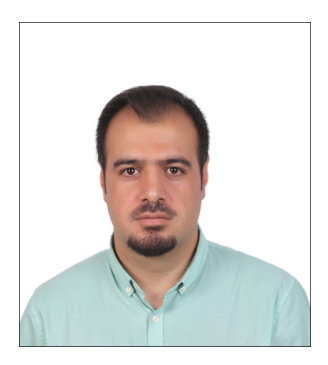

Vahid Maleki has received his MSc degree in Seismology at the University of Tehran, Iran in 2011. Vahid continued his academic career in Seismology as a PhD student at the University of Tehran. His research now focuses on the application of earthquake location techniques and seismic velocity structure in the Alborz Region, Iran.

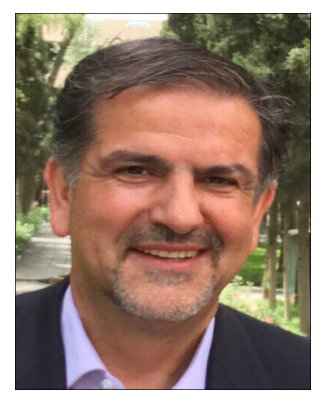

Mohammad Reza Hatami has studied Seismology at the University of Tehran, Iran. At present, Mohammad Reza is Assistant Professor Position at the Institute of Geophysics (IGUT). He works on different aspect of seismology such as, focal mechanism, earthquake relocation, ambient noise studies and seismic velocity structure.

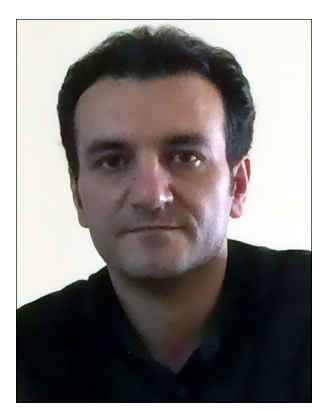

Ali Asghar Mottaghi has studied Seismology at the University of Tehran, Iran. In 2012, Ali accepted an Assistant Professor position at the International Institute of Earthquake Engineering and Seismology (IIEES). While working on ambient noise cross correlation based studies, he is a leading researcher on earthquake location techniques as well. In his early years at IIEES, Ali conducted a temporary seismic network to monitor local seismic activity in SW Iran. Now, He works on shallow subsurface imaging techniques using ambient noise data, and remains an active researcher. 